\title{
Perceptions of Acceptance: Evaluating World Wide Web Projects in Performance Reviews
}

\section{Kathleen Carlisle Fountain}

\begin{abstract}
Recent literature reveals that World Wide Web projects are beginning to receive more respect and acceptance from administrators. This survey studied the perceptions of librarian and teaching faculty Web creators in universities around the country to see if acceptance is on the rise. It found that respondents generally are satisfied with the recognition granted to their Web projects. Further findings indicate that institutional factors largely influence satisfaction levels. Librarians and teaching faculty can improve acceptance of Web projects only when submitting external reviews of their work to the evaluators.
\end{abstract}

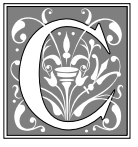

reative Web projects present complex and increasingly important challenges in the performance review process. Because such projects serve a variety of purposes, including supporting classes, sharing scholarly research, and providing guides to the Internet, during review, they pose merit questions unique from other examples of professional achievement (e.g., books and presentations). Web work often lacks elements commonly measured with existing scholarly schemas. The Web is a nebulous new medium requiring clear guidance to ensure that faculty pursue projects deemed valuable by their respective universities.

Recent literature shows a growing acceptance of another current publishing medium, electronic journal articles. Blaise Cronin and Kara Overfelt found that a sample of mathematics, computer science, English, and sociology programs modified their promotion and tenure guide- lines to adapt to faculty publishing in ejournals. With these findings, the authors called the concern over acceptance a "non-issue" and credited it to the merit criteria of peer review, which is applicable in both print and electronic mediums. ${ }^{1} \mathrm{~A}$ subsequent survey of business faculty supported this conclusion. ${ }^{2}$ Unlike articles in e-journals, Web projects are rarely peer reviewed, and the issue of acceptance remains very real.

For other nontraditional formats, studies of administrators indicate increasing approval. Nancy E. Seminoff and Shelley B. Wepner surveyed education faculty and deans around the country and discovered that the majority of the respondents viewed the value of technologybased projects (i.e., software and videos) equivalent to books and journal articles. ${ }^{3}$ Although Karen G. Lawson and Nancy L. Pelzer found that library administrators were open to accommodating technology-based projects (including Web

Kathleen Carlisle Fountain is Reference and Political Science Librarian in Meriam Library at California State University, Chico; e-mail: kfountain@csuchico.edu. 
sites) submitted in dossiers or portfolios, they identified a lack of uniformity in the standards used to evaluate them. ${ }^{4}$

Administrators and peer review committees may be open to new publishing formats, but anecdotal evidence shows that faculty are somewhat wary of entangling themselves with technology projects. ${ }^{5}$ As recently as 1997, faculty reported looking for new appointments at different institutions or abandoned their Web projects because of the lack of rewards. ${ }^{6}$ Furthermore, Lizbeth Langston recognized that the established methods of publishing and teaching will continue to be rewarded more often and consistently.

\section{When beginning this research, it was expected that librarians would report significantly more satisfaction with the perceived value of their Web projects than faculty would.}

To cope with this challenge, several authors suggested merit evaluation criteria to help demystify faculty expectations. ${ }^{8}$ Common recommendations include peer review (either solicited comments or prepublication editing), national or local recognition, and evidence of creativity or innovation. Professional groups also offer suggestions to evaluators for the review process to ensure that informed and capable committees judge digital work. $^{9}$

Because innovators choose to undertake nontraditional projects while these criteria evolve, this study aims to assess current faculty perceptions of the acceptance of their Web projects. It identifies the factors contributing to both how and why some projects are valued more than others, the ways in which the faculty themselves can improve the likelihood that their work will be valued, and challenges arising from the current models of assessment.

\section{Definitions}

For the purposes of this research, a Web project is defined as a creative work pub- lished solely on the Web. Material provided on the Web sites often replicates the style of traditional print publications. Among those included in this study are virtual libraries, subject-specific guides, digitized texts, directories, audio files, biographies, and encyclopedias. However, several survey respondents remarked that their work overlapped the boundaries of the print styles, illustrating the flexibility of Web publishing.

A creative site possesses original design and content. Just as a research project produces an original hypothesis, a Web project serves a unique purpose. The Web creator often selects the layout, images, text, and links that comprise the site's overall appearance and structure. The same person also provides the ongoing maintenance of links and enhancement of the content, with or without the help of others.

To be considered for this study, the sites needed to attribute the creation or maintenance to a specific person or persons rather than a whole institution or committee. Those generally disregarded in the selection process included online exhibits sponsored by various special collections departments and home pages for professional organizations. However, in both cases, if the site assigned primary creative responsibility to a specific individual, it was included within the parameters of the study.

\section{Hypothesis}

Although library administrators and academic deans express growing institutional acceptance of and support for electronic professional activities, librarians and teaching faculty (subsequently just called faculty) subject to performance reviews have yet to offer systematically their response. Using survey data, this article seeks to determine whether faculty feel that libraries and departments will seriously consider their electronic work in the form of Web projects in the performance review process.

When beginning this research, it was expected that librarians would report sig- 
nificantly more satisfaction with the perceived value of their Web projects than faculty would. "Taming the Web" by cataloging sites, creating subject guides, and teaching clientele to use Internet resources is increasingly commonplace in the librarian's daily work. Web projects, therefore, are a natural extension of librarianship in electronic format. Faculty depend more commonly on traditional forms of scholarship and research for positive performance reviews. For these reasons, the profession of the Web creator (librarian or faculty) was hypothesized to be the most significant cause of satisfaction with Web project recognition, with librarians as the most satisfied professionals.

\section{Methodology}

From among 6,200 sites available through the Librarians' Index to the Internet (LII), 151 Web projects were selected to draw the set of survey respondents. ${ }^{10}$ Each project resided on the server of a U.S. college or university and was attributed to at least one discrete author. By limiting the pool of respondents using these criteria, the responses focus on the experience of individuals whose Web work received the favorable external review of the LII. The underlying assumption of this selection is that each Web creator's site is meritorious in the eyes of the LII and, therefore, the author's institution is likely to view the site favorably, as well. The survey population consisted of two groups: librarians $(55 \%, \mathrm{n}=83)$ and teaching faculty $(45 \%, \mathrm{n}=68)$.

To limit the focus to the Web sites listed with the LII, the personalized cover letter stated the site found and asked the respondents to answer the questions based on experience with the identified site only. Questions about the content of the creators' Web project, institutional evaluation procedures, experience when submitting the Web project for review, and satisfaction levels helped to gauge the relationship between the institution and the perceptions of acceptance.

A presurvey postcard announced the upcoming survey to the respondents on
March 27, 2000, and the survey followed a week later. After allowing time for most of the surveys to return, a follow-up postcard was sent to nonrespondents on May 3,2000 . Of the 151 surveys distributed, 101 were returned. Two surveys lacked sufficient information to be included in the findings and were omitted from the data collection, leaving the number of valid surveys at 99 and an overall response rate of 65.5 percent. Sixty-one librarians and thirty-eight faculty provided valid responses. Among the faculty, thirteen were in the social sciences, eight in the physical and life sciences, and seventeen in the humanities. In the interest of equity, the various disciplines together formed the broader "teaching faculty" category to measure relationships to librarians. Not every respondent answered each of the twenty-one questions, so the descriptive statistics represent only the answers received.

\section{One question queried the way in which each respondent demon- strated the value of the Web project for performance or tenure reviews.}

\section{Findings}

\section{Demographics}

Nearly all survey respondents considered themselves the "creator/author" (91\%) of their site, rather than the "editor/maintainer," "coordinator," or "other." In addition, most of these Web creators voluntarily produced their Web projects. Two-thirds of all respondents characterized their participation as "completely voluntary," as opposed to "assigned" or "voluntary, but encouraged." As expected, librarians received more encouragement to create Web projects than faculty did.

Much of the literature categorizes and analyzes electronic work as scholarly literature, but the findings seem to dispute this presumption. The majority of survey respondents believed their Web projects could be evaluated within the "professional service or development" category $(42 \%)$. To a lesser extent, faculty and librarians felt their projects supported their 
"excellence in librarianship or teaching" (31\%) or "scholarship" (27\%), respectively.

From the responses received, it is clear that administrators are not communicating evaluation criteria to faculty. When asked how clearly their institution's guidelines addressed the evaluation of electronic or Web-based projects, an overwhelming majority of respondents said that the guidelines were unclear $(41 \%)$ or that written guidelines did not exist $(50 \%)$. This proves to be a significant hindrance to faculty satisfaction.

\section{Statistical Relevance}

Cross-tabulations measured the responses to two perception indicator questions against other survey questions such as tenure status, profession, and support received for site development. A chisquare test analyzed the probability of mere chance determining the answers. Where the probability value (or $p$ ) is low, chance as the determining factor decreases and the relationship between two variables increases. The correlation between the variables is significant when $p$ is less than .050, or five percent due to chance.

\section{How Web Projects Help Vitas and Reviews}

The first perception indicator question intended to determine the present value granted to Web projects. To ascertain how much the project itself contributed to a more accomplished curriculum vita and a positive performance review, this question asked: Overall, how helpful is your Web project to your vita and subsequent performance review? The possible responses included "very helpful," "somewhat helpful," "not very helpful," and "unknown." Because these questions asked the opinions of creators of sites of recognized worth, it was expected that the answers would reveal that their Web projects either helped or somewhat helped their vitas and reviews. More than 60 percent of the respondents confirmed that most respondents find that their Web projects are "very helpful" or "somewhat helpful."

Although librarians and faculty responded differently to this question, the chi-square test verified that profession

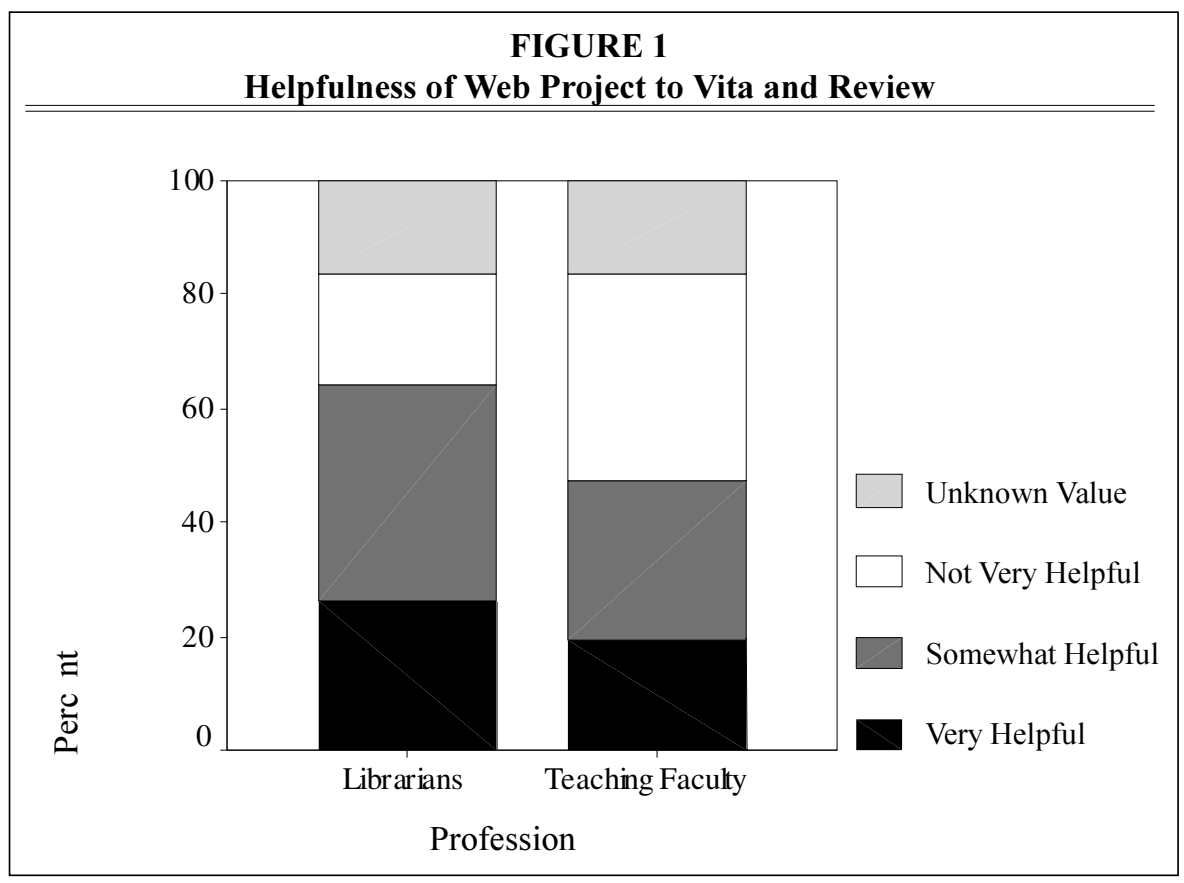


TABLE 1

Helpfulness of Web Project to Vita and Review

\begin{tabular}{|c|c|c|c|c|c|}
\hline & $\begin{array}{l}\text { Total } \\
\mathbf{N} \\
\end{array}$ & $\begin{array}{c}\text { Very } \\
\text { Helpful } \\
\% \text { (N) }\end{array}$ & $\begin{array}{c}\text { Somewhat } \\
\text { Helpful } \\
\% \text { (N) }\end{array}$ & $\begin{array}{c}\text { Not Very } \\
\text { Helpful } \\
\% \text { (N) }\end{array}$ & $\begin{array}{c}\text { Unknown } \\
\%(\mathrm{~N}) \\
\end{array}$ \\
\hline \multicolumn{6}{|c|}{ Presence of Department- or Library-Level Peer Review } \\
\hline No & 43 & $12(5)$ & $42(18)$ & $16(7)$ & $30(13)$ \\
\hline Yes & 52 & $33(17)$ & $27(14)$ & $35(18)$ & $6(3)$ \\
\hline Total & 95 & & & & \\
\hline \multicolumn{6}{|c|}{ Demonstrated Value of Project by Including Reviews } \\
\hline No & 35 & $17(6)$ & $31(11)$ & $29(10)$ & $23(8)$ \\
\hline Yes & 37 & $43(16)$ & $38(14)$ & $14(5)$ & $5(2)$ \\
\hline Total & 72 & & & & \\
\hline \multicolumn{6}{|l|}{ Assignment of Project } \\
\hline Assigned as part of job & 4 & $50(2)$ & $50(2)$ & 0 & 0 \\
\hline Voluntary, but encouraged & 30 & $43(13)$ & $30(9)$ & $13(4)$ & $13(4)$ \\
\hline Completely voluntary & 63 & $13(8)$ & $35(22)$ & $33(21)$ & $19(12)$ \\
\hline Total & 97 & & & & \\
\hline
\end{tabular}

does not reliably determine the value placed on an individual's Web project. As a descriptive comparison only, 26 percent of librarians thought that their Web projects were "very helpful" to their overall vitas, compared to 19 percent of faculty. In both professions, the respondents replied that Web projects were "somewhat helpful" more often than "very helpful," with 38 percent of librarians and 28 percent of faculty agreeing (see figure $1)$.

The presence of a department- or library-level peer review committee is the most significant factor contributing to the helpfulness of a Web project to the creator's vita $(p=.001)$. The percentage that believed that their Web project was "very helpful" increased for those whose institutions offered this level of peer review. Only 12 percent who did not have peer review felt that their Web project was "very helpful," but 33 percent with a peer evaluation believed that their project was "very helpful" (see table 1). Interestingly, this conflicts with other studies that report the inadequacy of peer groups to appreciate the work of junior faculty. ${ }^{11}$

One question queried the way in which each respondent demonstrated the value of the Web project for performance or tenure reviews. Answers revealed that submission of outside reviews was the most significant factor determining the perception of how much Web projects contribute to vitas and performance reviews $(p=.018)$. Such documentation proved more significant to the reviewing bodies than project descriptions, cited references, or Web site visits. In cases where a review was included with the dossier or portfolio, the respondents more often found their Web projects "very helpful" to their vitas and performance reviews (see table 1).

The final factor affecting the helpfulness of a Web project is assignment of the project. As previously stated, most of the 


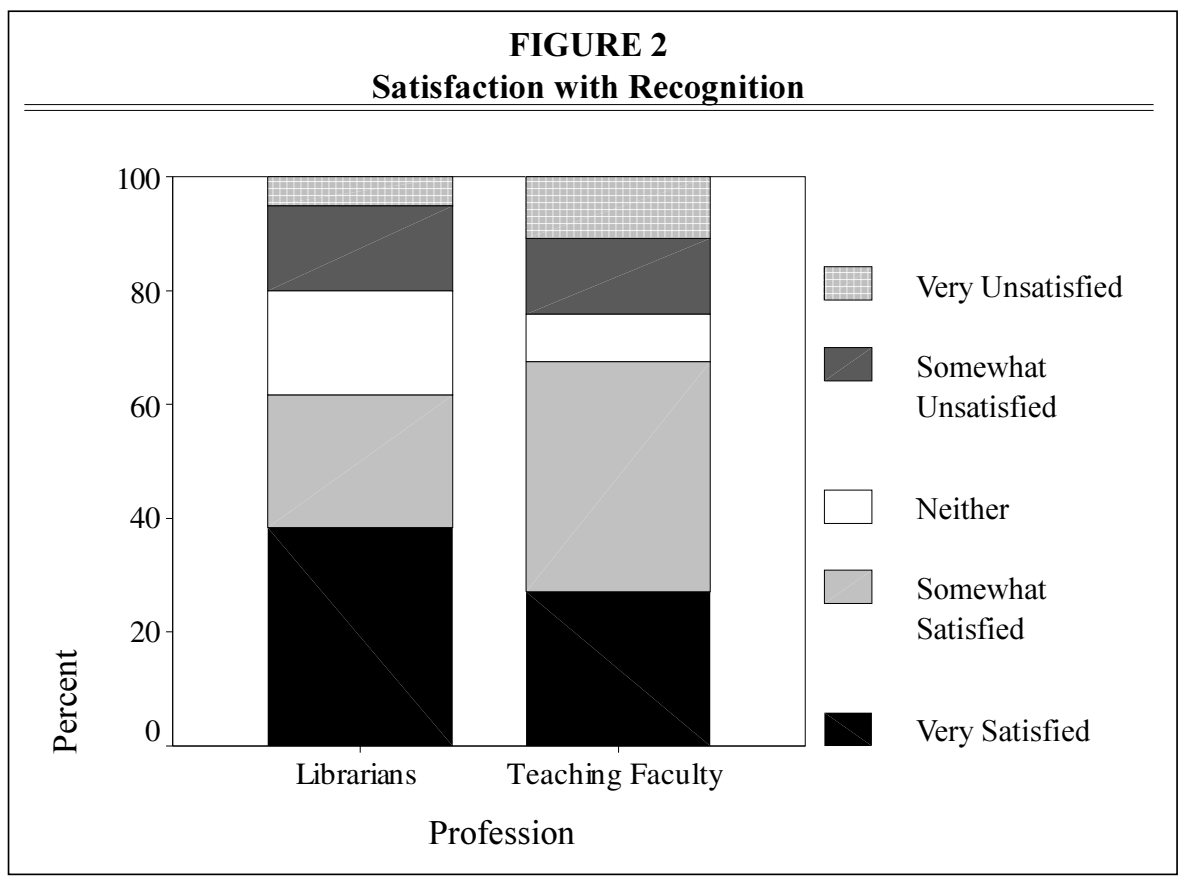

people surveyed responded that their Web project was a voluntary endeavor, with librarians more "encouraged" than faculty. The statistical relationship, however, conveys the risk associated with voluntary projects. When the project in question was either "assigned" or "voluntary, but encouraged," the perception of how helpful it is to a vita dramatically increases $(p=.020)$. The "voluntary" Web creators expressed a wider variety of responses, with an almost-equal number of respondents characterizing their project as "somewhat helpful" and "not very helpful" (see table 1).

\section{Web Creator Satisfaction}

A second perception question probed the respondents' feelings about institutional appreciation of Web projects by asking: How satisfied are you with the recognition granted to your Web project? This question offered a five-point scale from "very satisfied" to "very unsatisfied." Again, answers to the satisfaction question paralleled those from the helpfulness question. Sixty-four percent felt either "very satisfied" or "somewhat satisfied" with the recognition granted to their Web project by their institution. Another chisquare test verified that the original hypothesis of this study is invalid. Profession does not predict satisfaction with recognition. Again, librarians felt more satisfied, with 38 percent identifying themselves as "very satisfied" with the recognition granted to their Web projects. Faculty, on the other hand, garnered the highest rating in the "somewhat satisfied" category $(41 \%)$. Combining responses of "very satisfied" and "somewhat satisfied" indicated a great deal of satisfaction in both professions. Librarians and faculty selected these options at roughly equal rates, revealing no significant differences (see figure 2).

The strongest predictor of satisfaction is the clarity evident in the evaluation guidelines for electronic or Web projects of the respondent's institution $(p=.001)$. Although very few people responded that their institutions clarified the evaluation criteria, 89 percent of those who thought their guidelines were "very clear" or "somewhat clear" were "very satisfied" with their Web project's recognition. In 
instances where expectations for electronic projects are murkier, there was a greater discrepancy in satisfaction levels (see table 2).

As would be expected, receiving some element of support for a Web project led to more satisfaction with its recognition $(p=.011)$. Those who answered that their institution granted support selected one of the choices of staff assistance, technical help, funding, release time, or recognition; or, alternately, they offered additional answers of software, hardware, and server space. All together, 44 percent of respondents agreed that they were "very satisfied" with the recognition granted to their site, compared to only 15 percent who received no support. When combining the "very satisfied" and "somewhat satisfied" responses, those with support were still significantly more satisfied ( $75 \%$, compared to $42 \%$ ).

\section{Discussion}

\section{Evidence of Acceptance}

Web site creators who find themselves listed in the Librarian's Index to the Internet feel that publishing Web projects and submitting them with performance review materials is a satisfying experience. Administrators in the library and education fields voiced their growing acceptance of Web projects or other technology-based accomplishments, and the results and comments provide supporting evidence of that acceptance. "My Web work has been very well rewarded in annual reviews, equated to conventional publications," reported a tenured humanities professor. Another stated, "I rested my case for promotion to full professor entirely on the basis of my [instructional technology] projects. Although the battle was long drawn and 'ugly,' I was promoted."

Nevertheless, detractors remain. Two humanities professors noted the distinct lack of support or recognition in the comment section. One remarked, "Although my school appreciates the fact that I have established my site, they have no intention to reward or aid the ongoing upkeep." The other professor described an institutional environment that neither encouraged nor recognized Web projects and wrote, "Those who [make Web pages for teaching] do so on their own time." This lack of institutional support, as noted in the comments, may account for the 40 percent of respondents who did not feel that their Web projects helped their vitas or reviews.

\section{Scholarship versus Teaching versus \\ Service}

In the comments, a pattern emerged that reflected a split between valuing projects as scholarship, as teaching/librarianship, and as service/professional development in the review process. A tenure-track librarian mentioned, "Our librarians are specifically told that Web page development is definitely not a substitute for research and publication. Our Web pages are generally treated the same as traditional, print-based handouts or user

TABLE 2

Satisfaction with Institutional Recognition of Web Project

\begin{tabular}{lrrrrrr} 
Clarity of Evaluation & $\begin{array}{c}\text { Total } \\
\text { Guidelines }\end{array}$ & $\begin{array}{c}\text { Very } \\
\text { Satisfied } \\
\%(\mathrm{~N})\end{array}$ & $\begin{array}{c}\text { Somewhat } \\
\text { Satisfied } \\
\%(\mathrm{~N})\end{array}$ & $\begin{array}{r}\text { Neither } \\
\%(\mathrm{~N})\end{array}$ & $\begin{array}{c}\text { Somewhat } \\
\text { Unsatisfied } \\
\%(\mathrm{~N})\end{array}$ & $\begin{array}{c}\text { Very } \\
\text { Unsatisfied } \\
\%(\mathrm{~N})\end{array}$ \\
\hline Very clear & $\mathrm{N}$ & $100(1)$ & 0 & 0 & 0 & 0 \\
Somewhat clear & 8 & $87.5(7)$ & $12.5(1)$ & 0 & 0 & 0 \\
Not clear at all & 38 & $31.5(12)$ & $29(11)$ & $21(8)$ & $2.5(1)$ & $16(6)$ \\
No guidelines exist & 46 & $24(11)$ & $37(17)$ & $11(5)$ & $28(13)$ & 0 \\
\hline Total & 93 & $33(31)$ & $31(29)$ & $14(13)$ & $15(14)$ & $6(6)$ \\
\hline
\end{tabular}


guides." Citing his peer review committee, one respondent wrote, "The academic or scholarly value of a Web site publication or resource which is heavily use[d] and even rewarded ... remains problematic if examined under the light of traditional research and publication criteria."

This trend runs contrary to presumptions within the literature. Recommendations for evaluation criteria offer various methods of assessment with the assumption that the project is a scholarly endeavor. If a class-oriented Web site must meet the criteria of national recognition, for example, but only has a local audience, the evaluator(s) may find the site lacking merit. Therefore, institutions should identify how they view Web projects within each category and devise methods of evaluation accordingly.

However, if the site is indeed scholarly, this study found that Web creators could effectively demonstrate the value of their projects. Three of the most important criteria for determining scholarly merit in libraries and academic departments are scholarly contribution, local recognition, and national/international recognition. ${ }^{12}$ Citing or including external reviews of the Web project satisfies each of those criteria and, ultimately, contributes to the helpfulness of the project on one's vita. A tenured librarian commented, "Once the national recognition came, the library soon followed."

In the end, guidelines for evaluation are necessary to help guide faculty in their electronic endeavors. This is a problem for publication requirements in any format but is particularly troublesome for Web projects. ${ }^{13}$ Clarifying standards for determining merit of a project for both the Web creators and the review committees will produce a higher degree of satisfaction with institutional recognition.

\section{Perceptions and Satisfaction}

Some Web creators sense that a transition is under way. A humanities professor who created his Web project five years ago remarked that his institution's appreciation of his work has shifted in the past few years. Presently, there is a noticeable improvement in treatment.

Others find that although their Web projects may lack merit during review, the attention given them from outside the institution leads to opportunities for achievement in more traditional areas. For example, a tenured physical sciences professor commented that his Web project earned national awards and he subsequently received offers for "high-profile positions" with "several professional organizations." Such positions unquestionably support the standard service and professional development requirements of faculty positions. Still others received publishing opportunities, speaking engagements, and job offers in response to their Web work.

Although this survey measured satisfaction with respect to home institutions, an unexpected number of respondents felt their sites offered intrinsic rewards. In many cases, the survey respondents replied that their project supported several endeavors, such as their library's Web site, their research, their courses, or their personal interest. Furthermore, some reported significant recognition coming from outside the institution. One tenured librarian wrote, "As with most nonadministrative academic work ... the rewards and recognition are 'in kind,' coming from the community of scholars rather than the institution." A tenure-track humanities professor echoed that sentiment, "Faculty and administrators, with a few exceptions, seem either unaware or perhaps mildly interested in these resources. Mostly, they're indifferent. This doesn't disturb me because they are not the audience for whom I've created the site."

\section{Conclusion}

Although the profession of the survey respondent itself did not emerge as a reliable predictor of Web project acceptance, five different conditions help to determine how institutions respond to Web projects in the performance review process. Four institutional conditions improve the probability of higher faculty satisfaction ratings: clear evaluation 
guidelines for electronic materials, review by colleagues in the form of a department or library peer review committee, the presence of support, and assignment of the project. Teaching faculty and librarians, on the other hand, can improve their chances of a positive performance evaluation by including reviews of their Web project in their dossier.

Institutions are beginning to accommodate the Web endeavors of their librarians and faculty. As with any other technology-based project, institutional value will continue to evolve with the use of the medium. In 1997, administrators admitted their reluctance to reward Web projects, citing them as potentially a "short-lived fad."14 This study demonstrates a high degree of satisfaction by the Web creators and suggests that departments increasingly accept the Web as a durable, albeit complex, entity.

\section{Notes}

1. Blaise Cronin and Kara Overfelt, "E-journals and Tenure," Journal of the American Society for Information Science 46, no. 9 (Oct. 1995): 700-3.

2. Cheri Speier and Jonathan Palmer, "Faculty Perceptions of Electronic Journals as Scholarly Communication: A Question of Prestige and Legitimacy," Journal of the American Society for Information Science 50, no. 6 (May 1999): 537-43.

3. Nancy E. Seminoff and Shelley B. Wepner. "Are Technology-based Projects Valued as Scholarship for Tenure and Promotion?" Journal of Computing in Teacher Education 11, no. 3 (spring 1995): 5-10.

4. Karen G. Lawson and Nancy L. Pelzer, "Assessing Technology-based Projects for Promotion and/or Tenure in ARL Academic Libraries," College E Research Libraries 60 (Sept. 1999): 46476.

5. G. Phillip Cartwright, "Information Technology," Change 26, no. 5 (Sept. /Oct. 1994): 2628; Thomas J. DeLoughry, "Professors Report Progress in Gaining Recognition for Their Use of Technology," Chronicle of Higher Education 39, no. 26 (Mar. 3, 1993): A19, 21.

6. Lisa Guernsey, "Scholars Who Work with Technology Fear They Suffer in Tenure Reviews," Chronicle of Higher Education 43, no. 39 (June 6, 1997): A21-A22

7. Lizbeth Langston, "Scholarly Communication and Electronic Publication: Implications for Research, Advancement, and Promotion," in Untangling the Web: Proceedings of the Conference Sponsored by the Librarians Association of the University of California, Santa Barbara, and Friends of the UCSB Library (Apr. 26, 1996), available online at <http://www.library.ucsb.edu/untangle/ langston.html> (5 April 2000), ERIC ED 403892.

8. Suzanne Byron, "Computing and Other Instructional Technologies: Faculty Perceptions of Current Practices and Views of Future Challenges" (Denton, Tex.: Univ. of North Texas, 1995), ERIC ED 390381; Cartwright, "Information Technology," 26; Joan M. Leysen and William K. Black, "Peer Review in Carnegie Research Libraries," College E Research Libraries 59 (Nov. 1998): 512-22; Seminoff and Wepner, "Are Technology-based Projects Valued as Scholarship for Tenure and Promotion?" 8; _ "What Should We Know about Technology-based Projects for Tenure and Promotion?" Journal of Research on Computing in Education 30, no. 1 (fall 1997): 67-82.

9. CCCC Committee on Computers and Composition, "Promotion and Tenure Guidelines for Work with Technology," College Composition and Communication 51, no. 1 (Sept. 1, 1999): 13942; Modern Languages Association, Guidelines for Evaluating Work with Digital Media in the Modern Languages, May 30, 2000, available online at <http://www.mla.org/reports/ccet/ ccet_guidelines.htm> (5 June 2000).

10. The Librarians' Index to the Internet (http: / / www.lii.org) is a subject directory that compiles Web sites deemed useful for public libraries.

11. Ann E. Austin and R. Eugene Rice, "Making Tenure Viable," American Behavioral Scientist 41, no. 5 (Feb. 1998): 736-55.

12. Pamela S. Bradigan and Carol A. Mularski, "Evaluation of Academic Librarians' Publications for Tenure and Initial Promotion," Journal of Academic Librarianship 22, no. 5 (Sept. 1, 1996): 360-65; Lawson and Pelzer, "Assessing Technology-based Projects for Promotion and/or Tenure in ARL Academic Libraries," 470; Seminoff and Wepner, "What Should We Know about Technology-based Projects for Tenure and Promotion?" 70.

13. "Why Is Research the Rule? The Impact of Incentive Systems on Faculty Behavior," Change 32, no. 2 (Mar./Apr. 2000): 53-56.

14. Guernsey, "Scholars Who Work with Technology Fear They Suffer in Tenure Reviews," A22. 